\title{
Design and Implementation of Farm Monitoring and Security System
}

\author{
Ibam Emmanuel Onwuka \\ Department of Information \\ Systems \\ School of Computing \\ Federal University of \\ Technology Akure, Nigeria
}

\author{
Mark O. Afolabi \\ Department of Cyber Security \\ and Information Assurance \\ The Graduate School \\ University of Maryland \\ University College
}

\author{
Idowu O. John, Idowu A. \\ Olalekan \\ Department of Computer \\ Science School of Computing \\ Federal University of \\ Technology Akure, Nigeria
}

\begin{abstract}
Nigeria being an agricultural country needs some innovation in the field of agriculture. Monitoring and control of farming environment play an important role in farming production and management. Farm lands and plantations in Nigeria and African countries are usually very large scale running into hundreds of acres and in most cases fencing these large expanses of land can be prohibitively expensive and very stressful. Farmers therefore resort to building fences using sticks and ropes and these provide the only security measure they can adopt. These security measures are trivial and very ineffective as intruders can easily jump over them and cart away with as much crops as they can carry without the knowledge of the owners, especially when such fences are built around dark crevices. Also, with the present situations in Africa where farmers are facing security threats in their farms, especially with the Fulani herdsmen, the wireless sensor networks technology can be used in this effect to get real time information of the farm and know when an intrusion occurs, the nature or type of intrusion with the necessary action(s) to follow. The architecture of the WSNs system comprises of a set of sensor nodes, surveillance facilities and a base station that communicate with each other and gather information to make decisions about the situation at hand. The system overcomes the limitation of building fences using sticks which can be very much stressful. It also has the advantages of motion detection, an alarm and alert system as a security measure. One of the new features included in this work, is an alarm system which will be raised to scare the intruders to leave the farm premises. When the intruder stays for more than 30 seconds on the farmland, the GSM module is used for sending SMS to the farm owner indicating the nature of intrusion. It alerts the farmer that some human (mostly) or animals or birds are on the farm. The other feature includes the metallic sensor which informs the farm owner if a human being who intrudes the farm is armed (with metallic objects such as knife, cutlass, gun, etc.). The system is optimized with the aim of achieving maximum plant growth and yield.
\end{abstract}

\section{General Terms}

Agricultural, Farm, Security, Algorithm, Sensor.

\section{Keywords}

FMSS, WSNs, sensors, Precision Agriculture, Arduino, ZigBee, Microcontroller

\section{INTRODUCTION}

Generally, in the world, the economy of many countries is dependent upon agriculture. In spite of the economic growth and development, agriculture is the backbone of the economies all over the world. Agriculture contributes to the gross domestic product as it is the main stay of many countries. Agriculture meets food requirements of the people and serves as raw materials for several industries. There is always a huge loss of crops due to animal interference in agricultural land, crops are being destroyed and farmers are lost in large numbers [1].

Nigeria being an agricultural country needs some innovation in the field of agriculture. Farm lands and plantations in Nigeria and African countries are usually very large scale running into hundreds of acres and in most cases fencing these large expanses of land can be prohibitively expensive and very stressful. Farmers therefore resort to building fences using sticks and ropes and these provide the only security measure they can adopt. These security measures are trivial and very ineffective as intruders can easily jump over them and cart away with as much crops as they can carry them without the knowledge of the owners, especially when such fences are built around dark crevices.

Wireless sensor networks (WSNs) empower monitoring and controlling of corresponding physical environments from remote area with better efficiency and accuracy [2]. This work presents the design and the Implementation of WSNs for farm monitoring and security, which is easy to install. It is a microcontroller-based circuit to monitor and control intrusion by alerting the farm owner after the use of alarm on the farmland in order to scare aware intruders. The system is optimized with the aim of achieving maximum plant growth and yield.

This work is motivated by different views relating to farming security. The security measures employed by farmers in building fences using sticks and ropes as the only security measure, which can be very stressful and time consuming, and in turn limit farmers from farming on a large scale. The limitations of [1] and [3] as they only send alert to the farm owner on sensing intrusion without raising an alarm first before alerting the farmer. Many intruders which may be birds, animals or human will get scared and leave the farm premises immediately an alarm is raised. This will save the farm owner of the stress of going to the farm immediately after receiving an alert since an ordinary alarm will chase many animals away. Also, with the present situations in Africa where the farmers are facing security threats in their farms, especially with the herdsmen, the wireless sensor networks technology can be used in this effect to get real time information of the farm and know when an intrusion occurs with the necessary action(s) to follow.

\section{REVIEW OF RELATED WORKS}

In the past few years, new trends have emerged in the agricultural sector. The concept of precision agriculture has been around for some time now. Precision defined is a 
comprehensive system designed to optimize agricultural production by carefully tailoring soil and crop management to correspond to the unique condition found in each field while maintaining environmental quality [4], [5]. Wireless sensor network is a major technology that drives the development of precision agriculture.

Wireless sensor networks (WSNs) sometimes called wireless sensor and actuator networks (WSAN), described as spatially distributed autonomous sensors to monitor physical or environmental conditions, such as temperature, sound, pressure, etc. and to cooperatively pass their data through the network to a main location. The WSN applications development in precision agriculture has made it possible to increase efficiencies, productivity and profitability in many agricultural production systems, thereby minimizing unintended impacts on wildlife and the environment [6], [7]. WSN have been used for various applications in a range of fields like area monitoring which is a very common application area, others are health care monitoring, environmental/earth sensing and industrial monitoring to mention but few. The WSN is built of "nodes" - from a few to several hundreds or even thousands, where each node is connected to one (or sometimes several) sensors, like in [8]. Each sensor network node has typically five main components, which is determinant in designing a WSN for deployment, they are; radio transceiver, microcontroller unit, memory unit, sensor unit and an energy source.

[9], developed an intelligent security system for farm protection from wild animals. The system is to prohibit the entry of animals into the farm by designing a system that sounds when animals enters the farm and a flash light to focus on the area. Also uses a GSM module for alerting the farmers when there is an intrusion. It was motivated by the need to meet food requirements of the people and avoid farmer's financial losses as a result of animal intrusion on farmlands. He used PIC controller for much flash memory for project operation with proposed architecture used for farm protector system, it is easy to program and writing or burning devices are available. It also has inbuilt timers and preset mode to operate timers for farm protector; four relay is used for motor driving which are in forward direction by a relay that is directly connected to a controller. The system is complex for large scale handling and battery is always an issue.

[3], developed an embedded system for monitoring elephant intrusion in forest border areas using internet of things. The main aim is to alert the people in and around the forest border areas and to protect their lives and farm products. Also, to develop a prototype model for a real time interaction of elephant intrusion in forest border areas by making use of Internet of Things (IoT). He was considering the problem of detecting elephants in forest border areas using IoT. Enabling the sensing and actuating technologies using Raspberry Pi, the obtained data from the vibration sensor is sent serially to Raspberry Pi via Arduino.

[10], designed an automated farm management embedded system using internet of things. He explains the general installation method, the efficacy and how to use the monitor and control system in the growing environment by using the wireless sensor network technology. The project provides easy and convenient environment for growing plants by using temperature sensor, humidity sensor, illuminance sensor and water level sensor. Temperature and humidity are measured by Humidity Sensor Module and displayed on the LCD in real-time. As for the illuminance factor, the most common CDS sensor was used and MCU controls the LED bar with the light intensity data of the sensor. The water level sensor detects the water level of the basket and it is also displayed on the LCD. This system is composed of the water level measurement unit, sensor network-processing unit, sensor unit, and control unit.

[11], discuss wireless sensor network applications in the study of environment monitoring. Each node consists of microcontrollers, memory and transceiver. The microcontrollers are used to execute task, data processing and assist the functionality of other components in the sensor node. For the memory, it is mainly used for data storage while the transceiver acts from the combination of transmitter and receiver functions. They also discuss the recent development in the application areas of environmental monitoring system in order to assist people in their job and reduce cost and time. They observed that in order to implement a good environmental monitoring system, there are several requirements to be followed: autonomy, reliability, robustness and flexibility.

[12], developed a wireless sensor network based intrusion alert prototype for Human Elephant Conflict (HEC). They are being motivated by the conflict between humans and elephants, which are reported as a serious socio-economic problem in various regions in Africa and Asia. They want to address the HEC and to overcome limitations of the basic techniques used by agriculturalists at the boundaries of human settlement. The techniques they employed are: light and camera by using an arrays of modern motion sensitive camera traps to monitor wild animals; ultrasound has the ability to detect animals such as bats, dolphins, dogs, and cats; infra sound and seismic uses ground pressure due to elephant movements to detect them and proximity techniques to locate them; and wireless sensors used for monitoring and detection.

\section{SYSTEM MODELING AND DESIGN 3.1 System Model}

This work focuses on farm monitoring and security. To design a farm monitoring system based on wireless sensor networks (WSN), some of the components required are processor board, intrusion detection sensors, cameras, and buzzer alarms etc. In our work, wireless intrusion detector was used as a sensor. When human, animals or birds come in contact with the visualization of the cameras; the circuit will be grounded and will get an initial input signal that indicates presence of human, animals or birds on the farm land. The system will be activated, one of the new feature included in the work, which is an alarm will be raised to scare the intruders to leave the farm premises, when the intruder stay for more than 30 seconds on the farm land, the GSM module is used for sending SMS to the farm owner indicating the nature of intrusion. It alerts the farmer that some human (mostly) or animals or birds are on the farm. The other feature includes, the metallic sensor which informs the farm owner if a human being who intrudes the farm is armed (with metallic objects such as knife, cutlass, gun, etc.).

\subsection{Overall System Architecture}

Existing web-based monitoring systems such as WAGRIT have a structure that separates data acquisition devices and the web server. However, the proposed Farm Security Monitoring System has a structure that integrates the WSN sensors, CCTVs, database server, web server, etc. to collect information on the farm parameters and image information into a device for collecting various pieces of information on the environment, and provides real-time monitoring and various application services based on this information. 


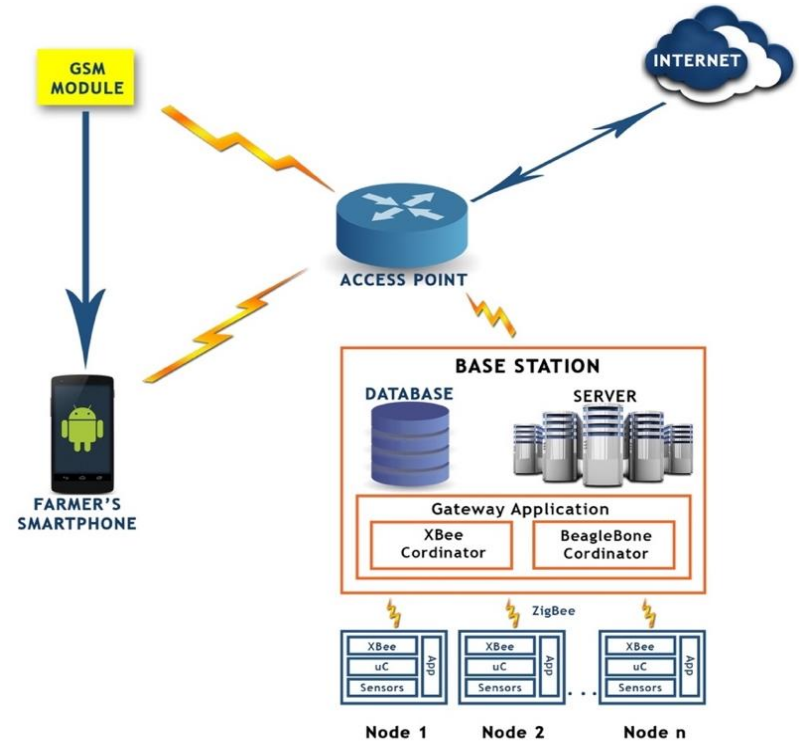

Figure 1: Overall system architecture of the Farm Monitoring and System

Figure 1 shows the Overall system architecture of the Farm Monitoring and security System. The system includes a base station, a number of distributed wireless sensor nodes, a number of buzzer alarms, predefined cameras that capture images and GSM modules.

The base station is the field position where all the equipment's are deployed. Each sensor node is a combination of sensors, microcontroller $(\mu \mathrm{C})$, and a $\mathrm{ZigBee}$ radio transceiver (i.e., the XBee module) with the inclusion of a user application program on each sensor node, which handles data from sensors in a certain well defined manner and communication with the base station. Various sensors like intrusion detection, metallic sensor, are attached to sensing node. Sensing node will read the values at regular interval and forward it directly to the coordinator. Sensing Nodes are XBee devices which are configurable for various sensors. XBee devices are capable of working on Solar Power as well as storage batteries. These devices are remotely configurable. The XBee module on the base station is configured as a coordinator and the XBee modules on the sensor nodes are configured as routers which accept values from various sensing nodes. Coordinator is connected to BeagleBone which is connected to internet. BeagleBone is a small low-power open-source hardware single-board computer. It can perform all operations which can be performed using any computer device. BB communicates with gateway/coordinator by serial interface and all accepted values will be sent to BB for processing. The smart phone application designed in Android is connected to Internet i.e. specifically to web server. From Smartphone, notifications can be received based on the events surrounding the farm parameters. Other devices like a buzzer alarm that will sound during the course of the intrusion; this creates a scary atmosphere for the intruder(s) in order to drive them away from the farm parameters. Also, the CCTV system is installed to detect the nature of intrusion either being human or animal. It collects image information on the parameters in real time to provide images of the nature of intrusion to the farmer

\subsection{Conceptual Framework of FMSS}

The conceptual framework of the Farm Monitoring and Security System as shown in Figure 2, has a structure that will integrate the WSN sensors (the intrusion detection and metallic sensors), CCTVs, GSM modules, database server, web server, etc. to collect information on the parameters of the farm and image information from a device for collecting various pieces of information on the environment, and provides real-time monitoring and various application services based on this information. As described in [13], it is divided into three layers. The middle layer, which supports communications between the physical layer and the application layer and converts the outdoors information collected from the physical layer into a database to provide data requested from the application layer which is equipped with interfaces to support various services for the farmer. The sensor coordinator (i.e. XBee Module) manages data acquisition from the intrusion sensors, extracts the data by processing the collected data packets into a format which could be stored in the database, and used for other processes.

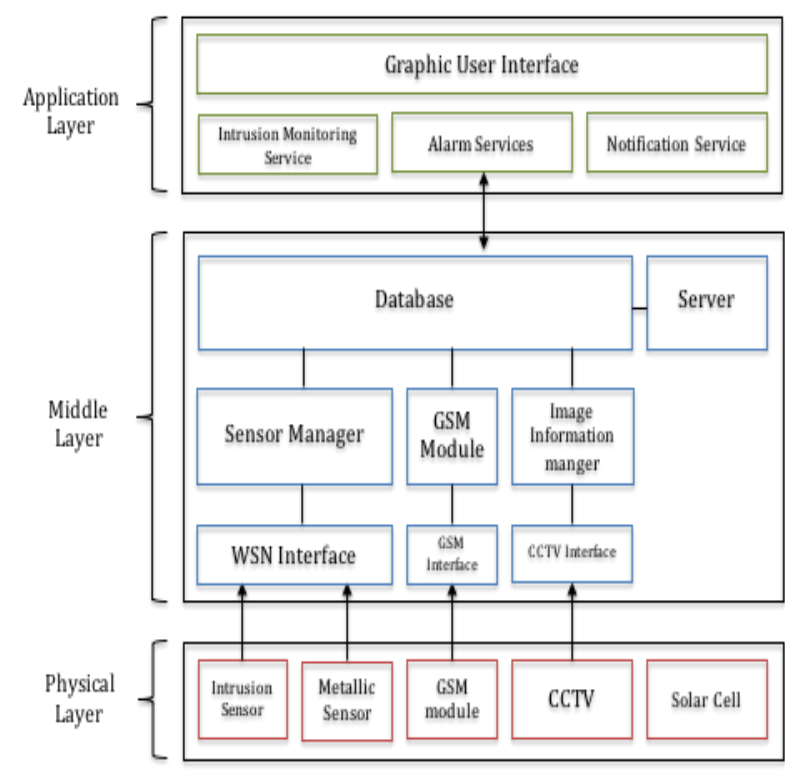

Figure 1: FMSS Conceptual Framework

\subsection{Use case Diagram}

As shown in figure 3, the user which is the farmer will have access to the home screen which contains the menu where the farmer put the system into a sleep mode or energy saving mode. The server login menu is where the user has access to the database and the server contents. The notification alert panel accommodates the notification sent from the system to the application. 


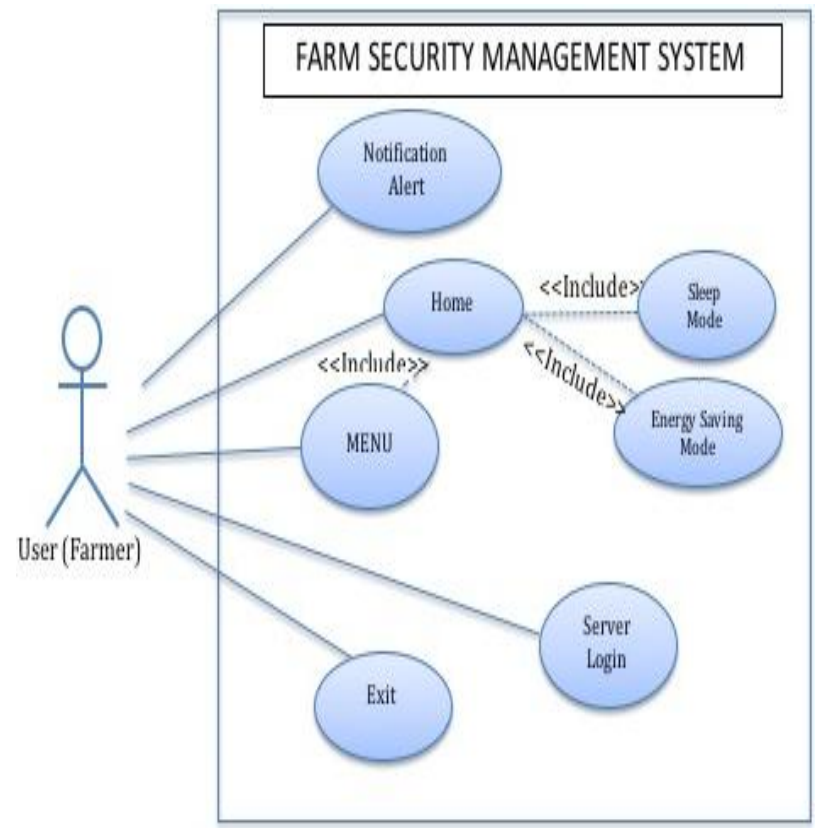

Figure 2: Use Case Diagram for FMSS Application

\subsection{System Algorithm}

The sequence of actions to be performed in the Farm Monitoring and Security Management System are:

Step 1: Initialize sensor system by farm owner or manager

Step 2: Begin data collection (sensors and cameras)

Step 3: If intrusion occur then activate timer, start

Timing

a. raise alarm on the farm for 30 seconds

b. if timing $>30 \mathrm{sec}$, then check intruder's status

c. if intruder status $=$ 'not present'(no) then goto step 2

d. else check intruder's height

e. if intruder's height $>2$ feet's then

i. activate camera, take picture of intruder(s)

ii. analyze picture (animal, human (armed or unarmed))

iii. send appropriate notification alert via internet or sms

Step 4: Check farmer's presence

a. if farmer is 'not present' goto step 2

b. else

i. $\quad$ set farmer's presence $=$ 'yes'

ii. switch system to sleeping mode or energy saving mode

\subsection{System Flowchart}

As shown in figure 4, the sensor systems check for intrusions continuously and collect information in a real-time. When an intrusion on the farmland is detected, an alarm sounds for not more than 30 seconds in order to scare the intruder away from the farm parameter. In a case where the intruder stays more than expected and the cameras still gives information of an intruder, a notification is sent to the farmer, notifying him of a longer stay of the intruder on the farm. The notification system uses the GSM module or the android application in notifying the farmer of the intrusion.

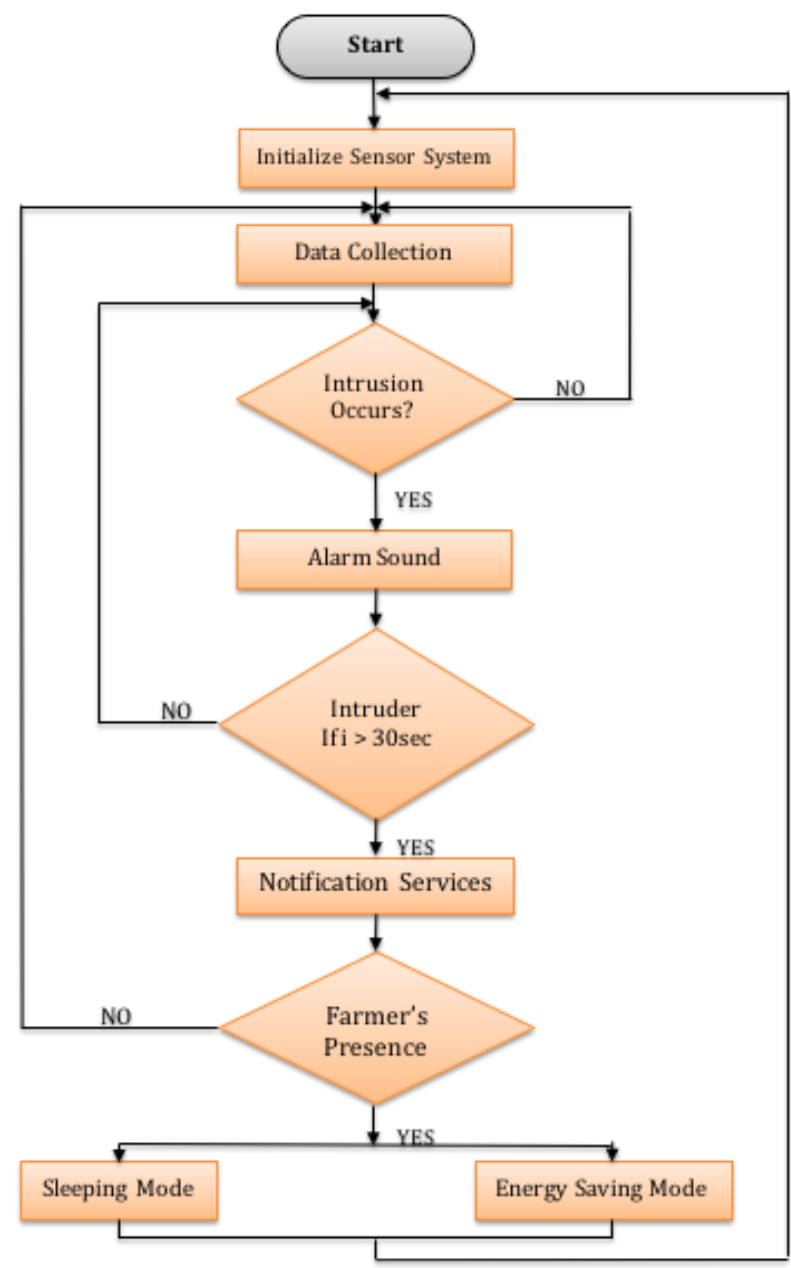

Figure 3: System Flowchart

\section{SYSTEM IMPLEMENTATION}

To verify the workability of the farm monitoring and security system presented in this paper, a prototype was developed, installed and the system was tested. A base station is developed using Arduino Due board which is connected to a system using USB connection. For security of the farm, intrusion detection system is deployed on each node. The FMSS monitors the environment and generates an alarm that scares intruders away, but at the longer stay of the intruders, it generates an alert notification that is sent to the farmers' smart phone app.

\subsection{Base Station}

The Base Station (BS) is responsible for receiving data from the sensor nodes and processing it as required. The microcontroller forms the heart of the BS and is responsible for enabling wireless communication, and displaying the received values on the android application and the on-board LCD. The microcontroller is connected to the sensors which consist of the motion detection sensor, alarm, electromagnetic sensor and camera. The microcontroller is interfaced with the XBee module. It is also interfaced with a mobile application using the gateway application. This is meant to forward the received data to the mobile app for displaying it on a GUI and further processing, decision making etc. as may be necessary. All the components in the BS are powered by a Power Unit. It consists of a battery or power supply (whichever is available). 


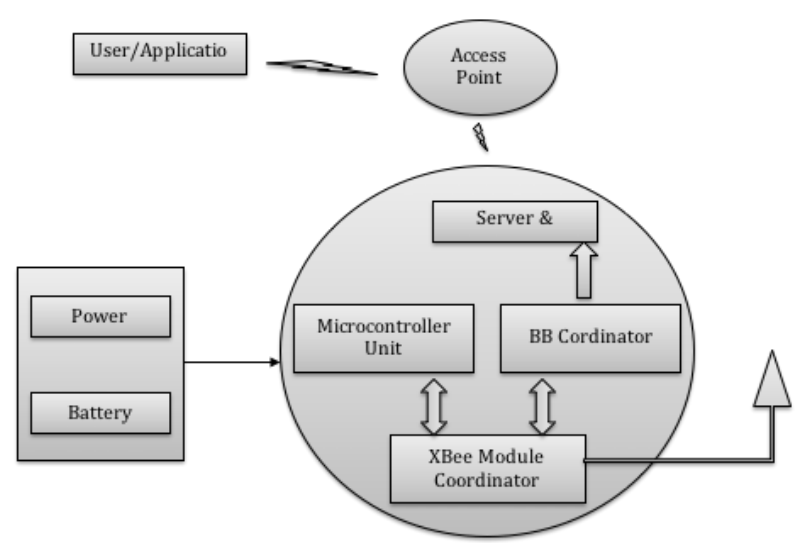

Figure 4: Base Station Layout

\subsection{Sensor Nodes}

The construction of the sensor node is similar to the BS. The SN consists of a microcontroller which collects sensor values from the on-board or remote sensors in the vicinity. These values are then incorporated into data packets and sent over the wireless link to another $\mathrm{SN}$ or to the BS depending on the location of the SN.

\subsection{Hardware Specification}

The configurations and specifications of the various hardware used for the system is shown in Table 1.

Table 1. Hardware Configuration and Specification

\begin{tabular}{|c|c|}
\hline Hardware Type & Hardware Specification \\
\hline $\begin{array}{l}\text { Microcontroller } \\
\text { Arduino Due }\end{array}$ & $\begin{array}{l}\text { Atmel SAM3X8E ARM } \\
\text { Cortex-M3 CPU } \\
\text { 32-bit ARM } \\
\text { microcontroller } \\
54 \text { digital input/output pins (of } \\
\text { which } 12 \text { can be used as PWM } \\
\text { outputs) } \\
12 \text { analog inputs } \\
4 \text { UARTs (hardware serial } \\
\text { ports) } \\
84 \text { MHz clock } \\
\text { USB OTG capable connection } \\
2 \text { DAC (digital to analog), } 2 \\
\text { TWI } \\
\text { a power jack, an SPI header, a } \\
\text { JTAG header } \\
\text { a reset button and an erase } \\
\text { button }\end{array}$ \\
\hline $\begin{array}{l}\text { HC-SR501 PIR Motion } \\
\text { Detector }\end{array}$ & $\begin{array}{l}\text { Based on infrared technology } \\
\text { Voltage:5V-20V } \\
\text { PowerConsumption:65mA } \\
\text { TTLoutput:3.3V,0V } \\
\text { Delay time: Adjustable }(.3- \\
>5 \mathrm{~min}) \\
\text { Locktime:0.2sec } \\
\text { Sensing range: less than } 120\end{array}$ \\
\hline
\end{tabular}

\begin{tabular}{|l|l|}
\hline & $\begin{array}{l}\text { degrees, within 7meters } \\
\text { Temperature: }-15 \sim+70\end{array}$ \\
\hline Grove Electromagnetic & $\begin{array}{l}\text { Working voltage, DC 5V } \\
\text { Groove Shape } \\
\text { Low standby current }\end{array}$ \\
\hline SD Card Module & $\begin{array}{l}\text { Direct pinout compatibility with } \\
\text { Arduino } \\
\text { Flash card slot switch } \\
\text { Support for microcontrollers }\end{array}$ \\
\hline LCD Display & $\begin{array}{l}\text { Interface with 8-bit or 4-bit } \\
\text { MPU } \\
192 \quad \text { Kind of alphabets, } \\
\text { numerals, symbols and special } \\
\text { characters can be displayed by } \\
\text { built in character generator } \\
\text { (ROM) light weight } \\
\text { Compact and lesign } \\
\text { Single power supply +5v drive }\end{array}$ \\
\hline
\end{tabular}

Unlike most Arduino boards, the Arduino Due board runs at $3.3 \mathrm{~V}$. The maximum voltage that the $\mathrm{I} / \mathrm{O}$ pins can tolerate is $3.3 \mathrm{~V}$. Applying voltages higher than $3.3 \mathrm{~V}$ to any $\mathrm{I} / \mathrm{O}$ pin could damage the board [14]. The board contains everything needed to support the microcontroller.

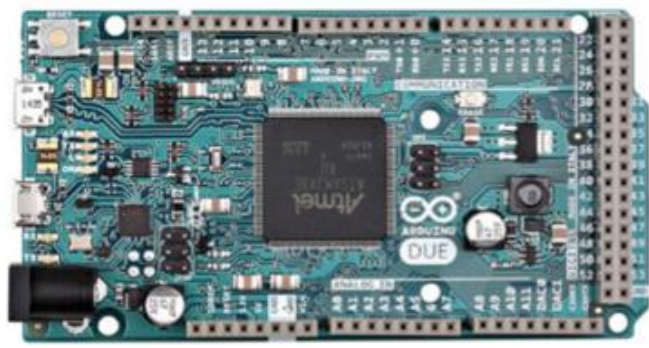

Figure 5: Diagram of an Arduino Board

\subsection{Software Description}

The Writing, compiling \& debugging of the program code is done by the use of Arduino sketch (version 1.8.0). Android studio was used to design the mobile application that displays the runtime activity of the Farm Monitoring and Security System. The application is developed with JAVA, and the coding of the hardware is done with $\mathrm{C}$ programming language.

\subsection{Application Interfaces}

Figure 7 shows the sensor activity log. The sensor activity log interface works with the base station; it displays the logs of all activities happening on the farm parameters. Each sensor is labeled as motion $\mathrm{A}$, motion $\mathrm{B}$, or motion $\mathrm{C}$, when an intrusion is detected, it displays on the application interface. The local video $\log$ is display on figure 8 , it keeps the $\log$ of all recorded videos for reference purpose. Figure 9 is the interface for the motion detection alarm; it takes a snapshot of the intruder and make a notification sound on the application. 


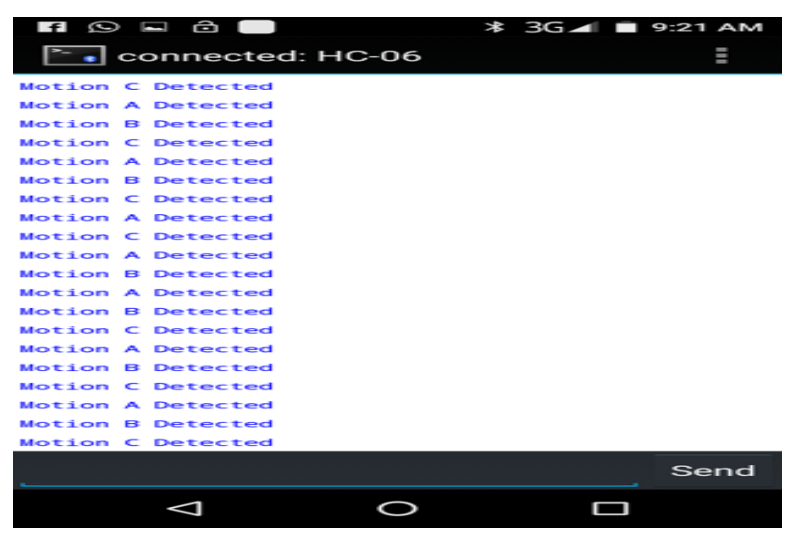

Figure 6: Activity Log Interface
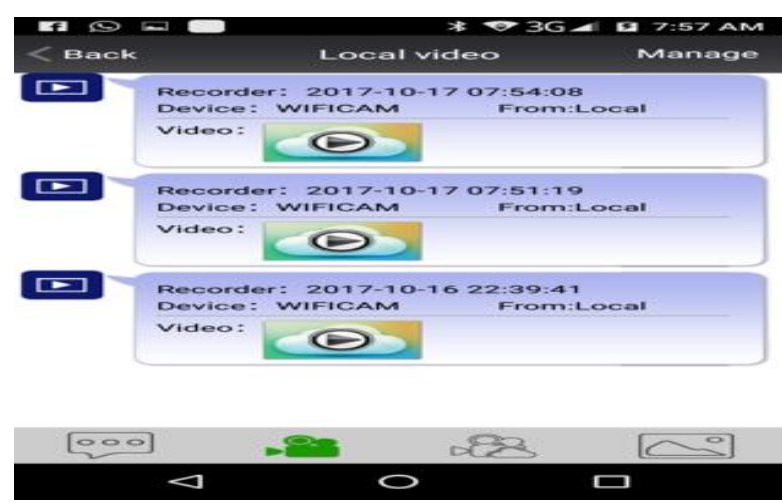

Figure 7: Video Log Interface

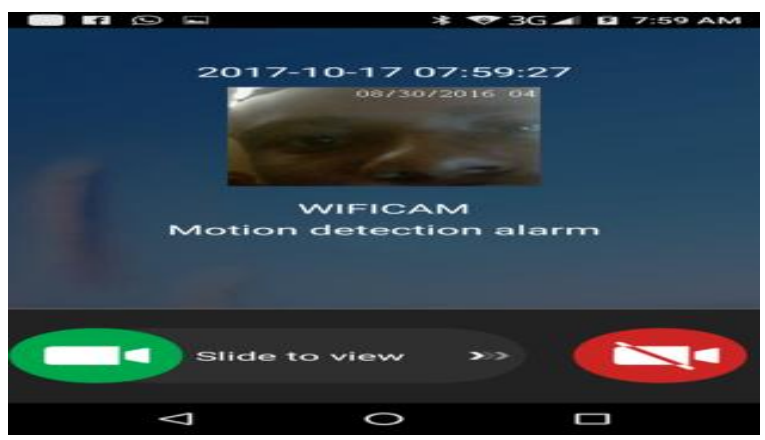

Figure 8: Motion Detection Alarm Display

\section{CONCLUSION AND FUTURE WORK}

WSNs have the potential to transform the security of farming in the agricultural sector of any nation. Integrating WSNs with existing services is also a possibility with promises of revolutionizing precision agriculture. Unlike other networks, WSNs are designed for specific applications. WSNs are becoming integral parts of our lives through various applications, even though each application differs in features and requirements. Since the system operation mainly depends on large scale farming, the system can be extended based on our interest. The model presented in this work can be adapted to many applications in the real world. The main idea is to have a system that is wireless and can be controlled through mobile devices even in remote areas. By creating wireless sensor nodes (WSN) to large scale farming, access to farm lands can be monitored and security enforced, thereby contributing to precision agriculture. Future works would focus on optimizing the entire system and incorporating automated defensive (attack) mechanisms to wade off intruders in farmlands.

\section{REFERENCES}

[1] Abhinav, V. D. 2016. Design and Implementation of an Intelligent Security System for Farm Protection from Wild Animals. International Journal of Science and Research (IJSR), Vol. 5 Issue 2, 2319-7064

[2] Willig, A. and Karl, H. 2005. Protocols and the Architectures for Wireless Sensor Networks. John Wiley and Sons Ltd.

[3] Maheswari R. 2016. Development of Embedded Based System to Monitor Elephant Intrusion in Forest Border Areas Using Internet Of Things. International Journal of Engineering Research, Vol.5, Issue 7, 594-598

[4] Blackmore S. 1994. Precision Farming: An Introduction. Outlook on Agriculture Journal, Vol. 23, No.4, 275- 280.

[5] Anjum A. and Reddy S. 2013. Monitoring for Precision Agriculture using Wireless Sensor Network - A Review. Global Journals Inc. (USA) Vol. 13, Issue 7, Version 1.0.

[6] Akyildiz I. F. and Kasimoglu I. H. 2004. Wireless Sensor and Actor Networks: Research Challenges. Ad Hoc Networks. 2 (4): 351-367.

[7] Aquino-Santos R ., González-Potes A., Edwards-Block A. and Virgen-Ortiz R. A. 2011. Developing a New Wireless Sensor Network Platform and Its Application in Precision Agriculture. Sensors, 11(1), 1192-1211.

[8] Arora A., Ramnath R., Ertin E., Sinha P., Bapat S., Naik V. and Kulathumani V. 2005. ExScal: Elements of an Extreme Scale Wireless Sensor Network. In Proceedings of the 11th IEEE International Conference on Embedded and RealTime Computing Systems and Applications RTCSA05, 102-108.

[9] Abhinav 2013. Design and Implementation of an Intelligent Security System for Farm Protection from Wild Animals. International Journal of Science and Research (IJRC), Volume 5, Issue 2, 956-959.

[10] Won H. C. and Min S. J. 2015. Automated Farm Management Embedded System using Internet of Things. Advanced Science and Technology Letters Vol.120 (GST 2015), 76-79

[11] Mohd F. O. and Khairunnisa S . 2012. Wireless Sensor Network Applications: A Study Environment Monitoring System. International Symposium on Robbotics and Intelligent Sensors (IR IS 2012), 1204-1210.

[12] Ruwini E. and Dileeka D. 2013. Wi-Alert: A Wireless Sensor Network Based Intrusion Alert Prototype for Hec, International Journal of Distributed and Parallel Systems (IJDPS) Vol.4, No.4.

[13] Jeonghwan H., Changsun S. and Hyun Y. 2010. Study on an Agricultural Environment Monitoring Server System using Wireless Sensor Networks, Sensors, 10, 1118911211 .

[14] Arduino 2017, Introduction. Accessed at https://www.arduino.cc/en/guide/introduction).arduino.cc 